\title{
BMJ
}

\section{Outcomes and costs of primary care surveillance and intervention for overweight or obese children: the LEAP 2 randomised controlled trial}

\author{
Melissa Wake, paediatrician, ' Louise A Baur, professor, ${ }^{1}$ Bibi Gerner, research officer, ${ }^{1}$ Kay Gibbons, head of \\ Nutrition and Food Services, ${ }^{1}$ Lisa Gold, health economist, ${ }^{4}$ Jane Gunn, professor, ${ }^{3}$ Penny Levickis, research \\ assistant, ${ }^{1}$ Zoë McCallum, paediatrician, ${ }^{1}$ Geraldine Naughton, director, ${ }^{5}$ Lena Sanci, research fellow, ${ }^{3}$ \\ Obioha C Ukoumunne, statistician ${ }^{1}$
}

${ }^{1}$ Royal Children's Hospital Murdoch Childrens Research Institute and University of Melbourne, Parkville, Vic 3052. Australia

${ }^{2}$ Discipline of Paediatrics and Child Health, University of Sydney and the Children's Hospital at Westmead, Westmead, NSW 2145, Sydney, Australia

${ }^{3}$ Department of General Practice, University of Melbourne

${ }^{4}$ Health Economics Unit, School of Health and Social Development, Deakin University, Burwood, Vic 3125, Australia

${ }^{5}$ Centre of Physical Activity Across the Lifespan, School of Exercise Science, Australian Catholic University, Strathfield NSW 2135, Australia

Correspondence to: $M$ Wake, Centre for Community Child Health, Royal Children's Hospital,

Flemington Rd, Parkville, Vic 3052,

Australiamelissa.wake@rch.org.au

Cite this as: BMJ 2009;339:b3308 doi:10.1136/bmi.b3308

\section{ABSTRACT}

Objective To determine whether ascertainment of childhood obesity by surveillance followed by structured secondary prevention in primary care improved outcomes in overweight or mildly obese children.

Design Randomised controlled trial nested within a baseline cross sectional survey of body mass index (BMI). Randomisation and outcomes measurement, but not participants, were blinded to group assignment.

Setting 45 family practices ( 66 general practitioners) in Melbourne, Australia.

Participants 3958 children visiting their general practitioner in May 2005-July 2006 were surveyed for BMI. Of these, 258 children aged 5 years 0 months up to their 10th birthday who were overweight or obese by International Obesity Taskforce criteria were randomised to intervention $(n=139)$ or control $(n=119)$ groups.

Children who were very obese (UK BMI z score $\geq 3.0$ ) were excluded.

Intervention Four standard consultations over 12 weeks targeting change in nutrition, physical activity, and sedentary behaviour, supported by purpose designed family materials.

Main outcomes measures Primary measure was BMI at 6 and 12 months after randomisation. Secondary measures were mean activity count/min by 7-day accelerometry, nutrition score from 4-day abbreviated food frequency diary, and child health related quality of life. Differences were adjusted for socioeconomic status, age, sex, and baseline BMI.

Results Of 781 eligible children, 258 (33\%) entered the trial; attrition was $3.1 \%$ at 6 months and $6.2 \%$ at 12 months. Adjusted mean differences (intervention control) at 6 and 12 months were, for BMI, -0.12 (95\% C -0.40 to $0.15, \mathrm{P}=0.4)$ and $-0.11(-0.45$ to $0.22, \mathrm{P}=0.5)$; for physical activity in counts/min, 24 ( -4 to $52, P=0.09)$ and 11 ( -26 to 49, $P=0.6$ ); and, for nutrition score, 0.2 $(-0.03$ to $0.4, P=0.1)$ and $0.1(-0.1$ to $0.4, P=0.2)$. There was no evidence of harm to the child. Costs to the healthcare system were significantly higher in the intervention arm.
Conclusions Primary care screening followed by brief counselling did not improve BMI, physical activity, or nutrition in overweight or mildly obese $5-10$ year olds, and it would be very costly if universally implemented. These findings are at odds with national policies in countries including the US, UK, and Australia.

Trial registration ISRCTN 52511065 (www.isrctn.org)

\section{INTRODUCTION}

Childhood obesity is now endemic in many countries. ${ }^{12}$ The long term physical, emotional, social, reproductive, and economic ramifications are likely to be immense. While prevention and intervention are expected to be needed throughout life for much of the population, effective strategies during childhood may best minimise psychosocial and physical morbidity. ${ }^{34}$ However, because of the sheer scale of the problem, tackling childhood obesity in the secondary or tertiary health care sector is not feasible for any but those who are most severely affected.

Primary care physicians, such as general practitioners (GPs), seem ideally placed to take on this issue because in many countries they are the only source of primary health care accessible to families across most of the social spectrum. GPs experience barriers in tackling childhood obesity, yet see it as extremely important and are optimistic that they can make a difference. ${ }^{56}$ National policies in countries including the United Kingdom, ${ }^{7}$ United States ${ }^{8}$ and Australia ${ }^{9}$ currently endorse the GP or family physician as central to surveillance for childhood overweight and obesity and counselling.

Evidence supporting such an approach in primary care, however, is conspicuously lacking. ${ }^{10}$ Despite high political appeal, two recent systematic reviews could not recommend screening because of the poor sensitivity and specificity of body mass index (BMI) cut points, lack of management strategies with demonstrated efficacy, and lack of evidence that benefits outweigh the harms. ${ }^{112}$ We could locate two trials (one randomised, ${ }^{13}$ one non-randomised ${ }^{14}$ ) in which a 
brief primary care intervention was offered to young children whose overweight/obese status was ascertained through office surveillance; neither was effective in reducing BMI relative to controls. However, both were hampered by small sample sizes, and, given the clear policy imperatives to locate childhood obesity management in primary care, further research is clearly warranted.

This paper reports 12 month outcomes from the LEAP2 randomised controlled trial. Its primary aim was to reduce BMI gain in overweight or mildly obese 5-10 year old children identified through surveillance in primary care. Secondary aims were to increase physical activity and improve child nutrition, to quantify any harms experienced by the child, and to compare the costs and consequences of the intervention from a health sector perspective.

\section{METHODS}

\section{Study design and setting}

A randomised controlled trial was nested within a large, cross sectional survey of BMI in family practices in Melbourne (population 3.7 million), Australia.

\section{General practitioner recruitment and education}

A non-representative sample of 66 general practitioners in 45 family medical practices was recruited by personalised letters sent to $1709 \mathrm{GPs}$ via a paediatric special interest group spanning 11 Melbourne divisions of general practice, the Health Insurance Commission, GPs from the LEAP1 trial, and contacts made through these networks; the letter was followed by recruitment evenings and practice visits. GPs attended two $2 \frac{1}{2}$ hour group training sessions for instruction in the "stages of change" mode ${ }^{15}$ and training in brief, solution focused, family therapy. ${ }^{16}$ They received a 30 minute DVD, developed for the trial, showing role model scenarios of GPs using solution focused therapy in consultations for healthy family lifestyle.

Each GP then conducted two simulated patient sessions (an "initial LEAP2 consultation" of 30 minutes, and a "follow-up consultation" of 20 minutes) during standard working hours supported by a mock patient file and materials. These visits mimicked the forthcoming intervention consultations, except that a child did not attend with the actor portraying the parent. After each consultation, the actor evaluated the GP's performance on 10 items, gave feedback to the GP, and communicated a summed "global score" (out of 10) via text message to the research team. GPs were paid \$A100 per simulated patient consultation. The two GPs who were given a global score $\leq 5$ for the second visit were offered an extra set of visits; one withdrew, while the other received higher scores and continued his involvement.

\section{Participants}

All children aged 5 years 0 months up to their 10th birthday attending participating practices for any reason during May 2005 to July 2006 were eligible to be invited into the BMI survey by practice staff.
Researchers also ran one or two dedicated measuring sessions in each of the larger practices, to which parents of all suitably aged children registered with the practice were invited by letter. Children in the survey were eligible for the trial if they were not receiving an ongoing weight management programme and were overweight or obese according to the cut-off points of the International Obesity Taskforce. ${ }^{17}$ Children were excluded if their BMI z score was $\geq 3.0$ (transformed using the LMS method ${ }^{18}$ and the 1990 UK Growth Reference ${ }^{19}$ ), on the basis that a brief secondary prevention approach was inappropriate. The research team then mailed an informed consent form and baseline questionnaire to interested parents with eligible children, and randomisation occurred once the completed forms were received by the research team. Follow-up was as close as possible to six and 12 months after randomisation, which equated to a mean of 9.0 months (SD 1.1) and 15.2 months (SD 1.2) from the baseline measurements. Thus, recruitment occurred in May 2005-July 2006, intervention delivery in October 2005-December 2006, the first follow-up in April 2006-March 2007, and the second follow-up in October 2006-September 2007.

\section{Randomisation}

Randomisation by child was stratified by GP and by overweight versus obese status; it was performed by an independent biostatistician using computer generated random numbers. The randomisation sequence was concealed from the study investigators, and the researchers collecting data remained blind to participants' trial status until follow-up was complete. Intervention families were notified by the non-blinded member of the research team (BG) and assisted in making the first doctor's appointment. Control families were notified via letter; general practice records of control children were subsequently audited to assess possible contamination (that is, attendances for discussion of weight). General practitioners knew the assignment status of any of their children who were in the intervention group, but did not otherwise know who among their large client base was enrolled in the survey or trial, so were generally unaware of control group membership.

\section{Intervention design}

The intervention had the same components as in the LEAP1 trial, ${ }^{20}$ designed using an intervention mapping technique within a behavioural epidemiology framework. GPs used a brief, solution focused approach ${ }^{21}$ to set and record appropriate, healthy lifestyle goals, assisted by a 16 page "family folder" written at a 12 year old reading level to be sure that virtually all parents could understand it. This folder included five topic sheets, each targeting one area of behavioural change (sedentary time, physical activity, water consumption, family eating habits, and lower fat options for food). Each sheet summarised supporting evidence, modelled solutions to challenges, and made suggestions as to how each goal might be reached. 


\section{Intervention delivery}

Before the first appointment, the GP received the child's named intervention materials, BMI, and a two page summary of parent responses from the baseline questionnaire regarding current nutrition, physical activity patterns, and concern regarding their child's weight status. Parents were offered four consultations over a 12 week period. Visit date, content discussed, and contracts made were recorded on a LEAP2 form in the child's medical record. If any "non-LEAP2" visits occurred, the GP was asked to reinforce any LEAP2 strategies previously discussed.

\section{Measures}

Follow-up data were collected via written parent questionnaire (at baseline and six and 12 months after randomisation), child questionnaire (at six and 12 months), anthropometric measurement (baseline and six and 12 months), and accelerometry measurement (six and 12 months). The primary outcome measure was BMI (weight $(\mathrm{kg}) /\left(\right.$ height $\left.\left.(\mathrm{m})^{2}\right)\right)$. Weight was measured in light clothing to the nearest $100 \mathrm{~g}$ using digital scales (Tanita, Japan, ModelTHD-646) and height was measured (twice) to the nearest $0.1 \mathrm{~cm}$ using a portable rigid stadiometer (Invicta, Oadby, Leicester, Model IPO955). The average of the height measurements was used in analyses; if the two differed by $\geq 0.5$ $\mathrm{cm}$ a third measurement was taken and the mean of the closest two values was used. BMI $\mathrm{z}$ score was also calculated using the US Centers for Disease Control (CDC) 2000 sex-specific BMI-for-age growth charts. ${ }^{22}$

Secondary outcome measures are shown in table 1. Socioeconomic status, a potential prognostic factor, was quantified using the Australian census based Index of Relative Socio-economic Disadvantage score for the participant's home postal code (mean score for Victoria 1020.3 (SD 59.4)). ${ }^{23}$ Costs were evaluated from a healthcare perspective and calculated in Australian dollars (\$A) at 2007 costs. Resources required to provide the LEAP2 intervention were recorded by the research team and via an audit of GP visits for intervention and control families. Resource use was valued using appropriate salary scales, travel cost allowances, and fee rates from the Medicare Benefits Schedule. ${ }^{24}$

\section{Sample size}

We aimed to reduce the expected increase in BMI from 0.8 to $\leq 0.5$ over 12 months. In the LEAP1 trial, the standard deviation of BMI values was 2.2 at both baseline and at 12 months after randomisation, and the correlation between the baseline and 12 month values was 0.88 . Using these values, we calculated that 190 overweight or mildly obese children in each group would ensure $80 \%$ power at the $5 \%$ level of significance (two sided) to detect a reduction in mean BMI increase as small as 0.3 units.

\begin{tabular}{|c|c|c|}
\hline Construct & Measure & Additional information \\
\hline Child waist circumference & $\begin{array}{l}\text { Lufkin Executive Steel Tape } \\
\text { (W606PM); measured }\end{array}$ & $\begin{array}{l}\text { Average of two waist measurements; if they differed by } \geq 1 \mathrm{~cm} \text {, a third measurement was } \\
\text { taken and the mean of the closest two used }\end{array}$ \\
\hline $\begin{array}{l}\text { Maternal and paternal body } \\
\text { mass index }\end{array}$ & $\begin{array}{l}\text { Weight }(\mathrm{kg}) /\left(\text { height }(\mathrm{m})^{2}\right) \\
\text { measured and self reported }\end{array}$ & $\begin{array}{l}\text { Baseline values reported for self and partner by responding parent. Values at } 6 \text { and } \\
12 \text { months measured for the parent(s) present with the child and reported; measured } \\
\text { data used preferentially }\end{array}$ \\
\hline Physical activity & $\begin{array}{l}\text { Actical Accelerometer (Mini } \\
\text { Mitter); measured }\end{array}$ & $\begin{array}{l}\text { Worn for } 7 \text { full days; } \geq 5 \text { valid days required. Valid days had } \geq 10 \text { hours of non-missing } \\
\text { data between } 6 \text { am- } 11 \mathrm{pm} \text {. Missing data were segments with } \geq 20 \text { minutes of consecutive } \\
\text { "0" counts, or counts }>0 \text { that were constant for } \geq 10 \text { minutes. Outcomes across all valid } \\
\text { days: mean activity counts } / \text { min, and \% time spent in moderate to vigorous physical } \\
\text { activity }\end{array}$ \\
\hline Physical activity & $\begin{array}{l}4 \text { day activity diary; parent } \\
\text { report }\end{array}$ & $\begin{array}{l}\text { Parent rating of child's activity on } 7 \text { point scale ( } 1=\text { sedentary, } 7=\text { intense activity) for each } \\
\text { of the } 1215 \text { - minute intervals between } 330 \mathrm{pm} \text { and } 630 \mathrm{pm} \text { over two weekdays and two } \\
\text { weekend days (total of } 48 \text { intervals at each follow-up). Ratings dichotomised as high }(\geq 4 \\
\text { ( } \geq \text { most children's play)) } v \text { low activity }\end{array}$ \\
\hline Nutrition & $\begin{array}{l}4 \text { day food diary; parent } \\
\text { report }\end{array}$ & $\begin{array}{l}\text { Parents reported child's consumption of each of } 10 \text { food and drink items }(0,1,2,12 \\
\text { times) for two weekdays and two weekend days, from which were derived dichotomous } \\
\text { ("yes" } v \text { "no") variables for five "healthy behaviours" (high fruit, vegetables, and water; low } \\
\text { fatty/sugary foods and non-diet sweet drinks) for each day. The number of healthy } \\
\text { behaviours per day was summed to give a score between } 0 \text { and } 5 \text { (higher score indicating } \\
\text { more healthy behaviour), thus providing } 4 \text { measurements at each wave }\end{array}$ \\
\hline Health status & $\begin{array}{l}\text { Paediatric quality of life } \\
\text { inventory (PedsQL 4.0) self } \\
\text { report and parent-proxy } \\
\text { versions }\end{array}$ & $\begin{array}{l}23 \text { items that yield total, physical summary, and psychosocial summary scores, each } \\
\text { with a possible range of } 0-100 \text { ( } 100=\text { best possible health); quantitative variable }\end{array}$ \\
\hline Body dissatisfaction & $\begin{array}{l}\text { Body figure perception } \\
\text { questionnaire }{ }^{35} \text {; child self } \\
\text { report }\end{array}$ & $\begin{array}{l}\text { Child picture scale of 1-7 ( } 1=\text { underweight, } 7=\text { obese) from which child picks perceived } \\
\text { and ideal selves. "Perceived" minus "Ideal" self yields a discrepancy index, with positive } \\
\text { and negatives scores representing desires to be thinner and fatter, respectively }\end{array}$ \\
\hline $\begin{array}{l}\text { Physical appearance and self } \\
\text { worth }\end{array}$ & $\begin{array}{l}\text { Modified from Harter's } \\
\text { perceived competence } \\
\text { scale; child self report }\end{array}$ & $\begin{array}{l}\text { Six pairs of statements with binary response format; children choose the statement from } \\
\text { each pair that is closest to their competence. Each of the } 6 \text { responses was then coded as } \\
\text { being either "positive/better perception" or "negative/worse perception". The } 6 \text { responses } \\
\text { were analysed as a single outcome }\end{array}$ \\
\hline
\end{tabular}




\section{Statistical analysis}

We used Stata 9.2 software. ${ }^{25}$ Participants were analysed in the groups to which they were randomised. Linear and logistic regression models (for quantitative and dichotomous outcomes respectively) were fitted for unadjusted and adjusted models. In the latter, all comparisons were adjusted for socioeconomic disadvantage, ${ }^{23}$ age at randomisation, sex, and baseline score for the outcome (where collected). All analyses except BMI z score were also adjusted for raw BMI at baseline.

For some outcomes, each subject accrued several scores (that is, the 48 scores for parents' reports of their child's physical activity and four scores for child's nutrition-see table 1). For these measures, random effects ("multilevel") models using maximum likelihood estimation ${ }^{26}$ for quantitative outcomes, and marginal models using generalised estimating equation ${ }^{27}$ for dichotomous outcomes, were fitted for the regression analyses to allow for within-subject correlation. The six dichotomous items on physical appearance and global self worth (see table 1) were analysed as a multivariate outcome, again using the generalised estimating equations method for logistic regression to allow for within-subject correlations.

Sensitivity analyses that additionally allowed for correlation between children seen by the same general practitioner provided essentially the same results as the main analyses, so we report only the latter here. Because some quantitative outcomes were non-symmetrical, results were validated using bias-corrected accelerated bootstrap confidence intervals. ${ }^{28}$

\section{RESULTS}

Table 2 reports baseline characteristics of the children, which were similar in the two trial arms. The location

Table 2 | Baseline characteristics of 258 overweight or mildly obese children aged 5-10 years who participated in study. Values are percentages (numbers) of participants unless stated otherwise

\begin{tabular}{|c|c|c|}
\hline Characteristic & $\begin{array}{l}\text { Intervention group } \\
\qquad(n=139)^{\star}\end{array}$ & Control group $(n=119)^{\star}$ \\
\hline Female & $60(83)$ & $61(73)$ \\
\hline Mean (SD) age (years) & $7.4(1.4)$ & $7.6(1.4)$ \\
\hline Mean (SD) social disadvantage score & $1028(70)$ & $1028(63)$ \\
\hline \multicolumn{3}{|l|}{ Maternal education: } \\
\hline Did not complete high school & $31(42)$ & $33(39)$ \\
\hline Completed high school & $35(47)$ & $32(38)$ \\
\hline University degree & $34(45)$ & $34(40)$ \\
\hline \multicolumn{3}{|l|}{ BMI category†: } \\
\hline Overweight & $75(104)$ & $78(93)$ \\
\hline Obese & $25(35)$ & $22(26)$ \\
\hline Mean (SD) BMI & $20.2(2.3)$ & $20.3(1.9)$ \\
\hline Mean (SD) BMI z-score & $1.9(0.5)$ & $1.9(0.5)$ \\
\hline Mean (SD) physical activity score & $3.4(0.8)$ & $3.4(0.8)$ \\
\hline$\%$ time spent in high activity (parent report) & $24.2 \%$ & $22.1 \%$ \\
\hline Mean (SD) nutrition score & $3.7(1.1)$ & $3.5(1.2)$ \\
\hline Mean (SD) PedsQL (parent report) & $74.6(14.3)$ & $74.6(14.5)$ \\
\hline
\end{tabular}

$\mathrm{BMI}=$ body mass index. PedsQL=paediatric quality of life inventory.

*Sample size ranges from 131 to 139 in intervention arm and 111 to 119 in control arm.

†Based on cut points of International Obesity Taskforce. of participating practices covered the sociodemographic spectrum, with the median practice close to the 50 th centile (range from $<10$ th to $>90$ th centile) on the Index of Relative Socio-economic Disadvantage. ${ }^{23}$

The figure shows the participant flow throughout the trial: 139 and 119 participants were allocated to the intervention and control arms, respectively. Overall attrition rates for anthropometry data collection was $3.1 \%(250)$ at six months and 6.2\% (242) at 12 months. Completion rates at six and 12 months, respectively, for questionnaires were $97.3 \%$ (251) and 91.9\% (237); 89.5\% (231) and 77.9\% (201) for useable accelerometry data; and $93.8 \%(242)$ and $88.4 \%(228)$ for 4 day food and nutrition diaries.

\section{Primary outcome (body mass index)}

Tables 3 and 4 show unadjusted and adjusted outcome comparisons between the intervention and control arms at six months and 12 months after randomisation respectively. At six months, the adjusted mean BMI of the intervention group was 0.12 lower than that of the control group (adjusted mean difference -0.12 (95\% CI -0.40 to $0.15, \mathrm{P}=0.38)$, and, at 12 months, the adjusted mean BMI was 0.11 lower (adjusted mean difference $-0.11(-0.45$ to $0.22, \mathrm{P}=0.51)$. Mean $\mathrm{BMI} z$ score (not shown) and waist circumference were similar in the two trial arms.

\section{Secondary outcomes}

Overall physical activity, as measured by accelerometry, was slightly but not significantly higher in the intervention than control group at six months (mean difference 24 counts $/ \mathrm{min}(95 \% \mathrm{CI}-4$ to $52, \mathrm{P}=0.09))$ and at 12 months (mean difference 11 counts/min $(-26$ to $49, \mathrm{P}=0.55)$ ). Similarly, overall nutrition scores were only marginally better in the intervention group (mean difference at six months $0.2(95 \% \mathrm{CI}-0.03$ to 0.4 , $\mathrm{P}=0.10)$ and at 12 months $0.1(-0.1$ to $0.4, \mathrm{P}=0.24))$. Parents reported lower consumption of soft drinks in the intervention group at both time points, but no marked differences in fruit, vegetable, fat, or water consumption.

There was no evidence that the intervention was harmful as perceived by the children, whose reports of health related quality of life, body dissatisfaction, and self esteem were similar to those of control children. Compared with control parents, however, parents in the intervention group reported improved child health related quality of life at six months (mean difference 3.1 points higher (95\% CI 0.6 to 5.7, $\mathrm{P}=0.02)$ ) and at 12 months (3.1 points higher (0.2 to $6.0, \mathrm{P}=0.03)$ ), which was evident for both the physical and psychosocial summary scores.

\section{Process evaluation}

All GPs attended at least one of the GP education sessions - $65(98.5 \%)$ attended the first, and $64(97 \%)$ attended the second - and all completed the two simulated patient consultations. 


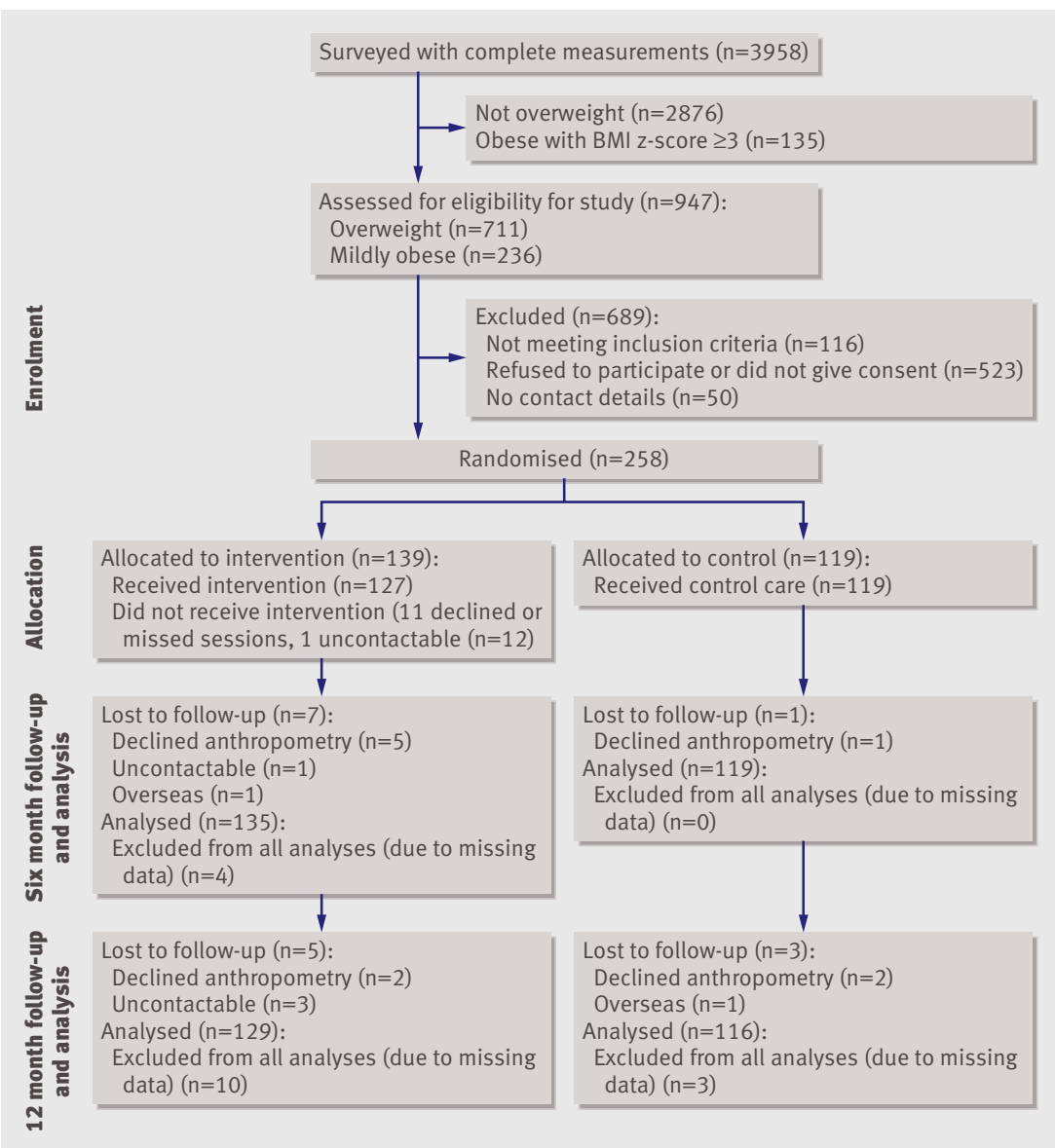

Fig 1| Flow of participants in trial intervention were provided to a greater number of children per GP — for example, to \$A412 (95\% CI \$A381 to $\$$ A442) if each GP managed 30 children. This still, however, represents a marked increase in costs for no real improvement in the primary or secondary outcomes.

\section{Meta-analysis}

Although we aimed for 190 children in each arm of this trial, only 127 remained in the intervention arm and 115 in the control arm at 12 months. This meant that the smallest difference in BMI between the trial arms that could be detected with $80 \%$ power was 0.38 , rather than the desired 0.30 . However, the similarity of design and content provided an opportunity to combine the results from both LEAP trials in a meta-analysis. With a combined total of 196 subjects in the intervention arm and 191 subjects in the control arm at 12 months, the smallest BMI difference detectable with $80 \%$ power was 0.30. A fixed effects meta-analysis of combined LEAP2 and LEAP1 data showed that the adjusted mean BMI difference at six months was $-0.16(95 \%$ CI -0.38 to 0.06$)$ and at 12 months was $-0.06(-0.34$ to 0.22 ). Thus, although a mean improvement in the intervention arm as large as $0.3-0.4$ is possible, the body of evidence points towards no important difference between the trial arms.

\section{Post hoc analyses}

Since national policies often use the proportion overweight, rather than mean BMI, as the target for assessing effective intervention, we also examined outcomes according to dichotomised BMI (that is, overweight/obese versus not overweight/obese) using the International Obesity Taskforce cut points. At 12 months, $77.2 \%$ of the LEAP2 intervention children remained overweight/obese compared with $82.6 \%$ of the controls (difference $-5.4 \%$ (95\% CI $-15.5 \%$ to $4.6 \%, \mathrm{P}=0.29))$. Similar values were obtained in the meta-analysis $(80.2 \%$ v 84.8\%; difference $-4.6 \%(-12.2 \%$ to $2.9 \%, \mathrm{P}=0.23))$.

There was no evidence at the $5 \%$ level in adjusted models that socioeconomic status (using scores from the disadvantage index) modified the effect of the intervention on the main outcomes of BMI, activity, or nutrition at six or 12 months. Similarly, there was no strong evidence that attending more consultations improved $\mathrm{BMI}$ at six months $(\mathrm{P}=0.18)$ or at 12 months $(\mathrm{P}=0.60)$ after adjustment for baseline $\mathrm{BMI}$.

\section{DISCUSSION}

\section{Principal findings}

This trial suggests that current international policy directions for primary care surveillance and brief counselling are unlikely to be effective in reducing childhood obesity. Neither the primary outcome (BMI) nor key secondary outcomes (physical activity, nutrition, parental BMI) showed marked improvement. Although there was no evidence that the child experienced physical or psychosocial harm as a result of the intervention, a significant investment of healthcare 
resources was incurred that could be used to greater effect elsewhere.

\section{Strengths and limitations of study}

Strengths of the study include its randomised design, the objective measures of anthropometry and physical activity, the strong uptake by families and GP practices spanning the range of socioeconomic status, follow-up for a full year, and the extremely high retention rate. Because of the large sample size, the confidence intervals were sufficiently narrow to conclude that any benefit to BMI trajectory was not clinically important. There was no evidence that contamination explains the null findings. Though we could not be sure that GPs implemented the intervention as intended, GPs could only proceed to LEAP families once the two simulated patient visits had been delivered satisfactorily.

Limitations include the select volunteer nature of the participating GPs, but it seems unlikely that less committed or interested GPs would achieve a better result. Only a third of the families with a child identified as eligible chose to take up the intervention; again, it seems unlikely that those who were not recruited to the trial would have fared better, and this would be a problem at the public health level only had the intervention been effective. It was not possible to blind the families to group membership, but this limitation would typically be expected to increase, not reduce, between-group differences on self reported measures.

\section{Interpretation in light of other studies}

These negative findings are congruent with two smaller trials of brief, individualised primary care approaches targeting overweight or mildly obese children identified by screening. ${ }^{1314}$ Therefore, the most likely interpretation is that such interventions are ineffective in reducing BMI. This could be due to insufficient intervention intensity or duration; in recent studies in tertiary obesity clinics, sustained BMI reduction occurred only when interventions occurred over 9-12 months. ${ }^{29}$ Interventions in this BMI range might be more effective when initiated by families seeking help rather than via a screening process. However, this would be unlikely to address the public health issue adequately, as only a minority are sufficiently concerned to seek help for their overweight children, and individual effects have uniformly been modest ${ }^{3132}$ or absent. ${ }^{33}$

\section{Conclusions and policy implications}

This brief, physician led, primary care intervention produced no long term improvement in children's BMI, physical activity, or nutrition. These findings cast doubt on many countries' current policies that support universal surveillance coupled with brief, individualised secondary prevention by the primary care sector to reduce childhood obesity. Thus far, each new study has progressively added weight to the view that overweight and mild obesity in primary school

\begin{tabular}{|c|c|c|c|c|c|c|c|c|}
\hline \multirow[b]{2}{*}{ Outcome } & \multicolumn{2}{|c|}{ Intervention } & \multicolumn{2}{|c|}{ Control } & \multicolumn{2}{|c|}{ Unadjusted difference } & \multicolumn{2}{|c|}{ Adjusted difference $\dagger$} \\
\hline & $\begin{array}{c}\text { No of } \\
\text { participants }\end{array}$ & Measure* & $\begin{array}{c}\text { No of } \\
\text { participants }\end{array}$ & Measure* & Mean $(95 \% \mathrm{Cl})$ & P value & Mean $(95 \% \mathrm{Cl})$ & $P$ value \\
\hline \multicolumn{9}{|l|}{ Anthropometry: } \\
\hline Child BMI & 132 & $20.5(2.6)$ & 118 & $20.6(2.2)$ & $-0.13(-0.74$ to 0.48$)$ & 0.7 & $-0.12(-0.40$ to 0.15$)$ & 0.4 \\
\hline Child waist circumference & 131 & $70.1(8.4)$ & 117 & $70.4(8.2)$ & $-0.30(-2.37$ to 1.77$)$ & 0.8 & $0.12(-0.98$ to 1.22$)$ & 0.8 \\
\hline Maternal BMI & 125 & $28.4(5.7)$ & 115 & $27.3(5.1)$ & $1.08(-0.31$ to 2.47$)$ & 0.1 & $0.18(-0.27$ to 0.64$)$ & 0.4 \\
\hline Paternal BMI & 101 & $27.9(4.0)$ & 83 & $27.9(3.7)$ & $-0.08(-1.20$ to 1.05$)$ & 0.9 & $-0.21(-0.72$ to 0.30$)$ & 0.4 \\
\hline \multicolumn{9}{|l|}{ Accelerometry: } \\
\hline Activity (counts/min) & 122 & $346(120)$ & 109 & $320(100)$ & $26(-3$ to 54$)$ & 0.08 & 24 (-4 to 52$)$ & 0.09 \\
\hline$\%$ of time spent in MVPA & 122 & $16.1(5.5)$ & 109 & $15.2(4.3)$ & 0.9 (-0.4 to 2.2$)$ & 0.2 & 0.7 (-0.5 to 2.0$)$ & 0.2 \\
\hline \multicolumn{9}{|l|}{ Parent-proxy report: } \\
\hline "High" v"low" activity & 127 & $18.3 \%$ & 115 & $19.8 \%$ & $0.82(0.61$ to 1.09$) \ddagger$ & 0.2 & $0.75(0.55$ to 1.04$) \ddagger$ & 0.08 \\
\hline Nutrition score & 125 & $3.9(1.0)$ & 114 & $3.6(1.2)$ & 0.3 (0.1 to 0.5$)$ & 0.01 & $0.2(-0.03$ to 0.4$)$ & 0.1 \\
\hline PedsQL total: & 133 & $77.6(12.8)$ & 118 & 74.5 (14.1) & $3.2(-0.2$ to 6.5$)$ & 0.06 & $3.1(0.6$ to 5.7$)$ & 0.02 \\
\hline Physical summary & 133 & $80.2(16.6)$ & 118 & $76.0(17.7)$ & $4.2(-0.1$ to 8.4$)$ & 0.06 & $4.0(0.6$ to 7.3$)$ & 0.02 \\
\hline Psychosocial summary & 133 & $76.3(12.6)$ & 118 & 73.7 (13.9) & $2.6(-0.7$ to 5.9$)$ & 0.1 & $2.7(-0.001$ to 5.3$)$ & 0.05 \\
\hline \multicolumn{9}{|l|}{ Child self report: } \\
\hline PedsQL total: & 130 & $78.8(12.3)$ & 117 & $77.8(11.8)$ & $1.0(-2.1$ to 4.0$)$ & 0.5 & $1.3(-1.7$ to 4.4$)$ & 0.4 \\
\hline Physical summary & 130 & $82.6(11.6)$ & 116 & 82.1 (11.6) & $0.5(-2.4$ to 3.4$)$ & 0.7 & $0.6(-2.4$ to 3.6$)$ & 0.7 \\
\hline Psychosocial summary & 130 & $76.7(14.5)$ & 116 & $75.4(14.2)$ & $1.3(-2.4$ to 4.9$)$ & 0.5 & $1.8(-1.8$ to 5.5$)$ & 0.3 \\
\hline Body dissatisfaction & 130 & $1.1(1.0)$ & 115 & $1.0(1.0)$ & $0.11(-0.15$ to 0.36$)$ & 0.4 & $0.09(-0.17$ to 0.34$)$ & 0.5 \\
\hline $\begin{array}{l}\text { "Positive" v "negative" } \\
\text { appearance/self worth }\end{array}$ & 130 & $70.1 \%$ & 115 & $69.6 \%$ & $1.05(0.75$ to 1.48$) \ddagger$ & 0.8 & 1.12 (0.79 to 1.58$) \ddagger$ & 0.5 \\
\hline
\end{tabular}

BMI=body mass index. MVPA=moderate to vigorous physical activity. PedsQL=paediatric quality of life inventory.

*Values are means (standard deviations) unless stated otherwise. Mean differences are shown for quantitative outcomes and odds ratios for dichotomous outcomes.

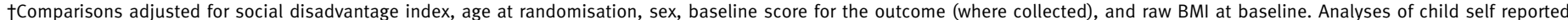

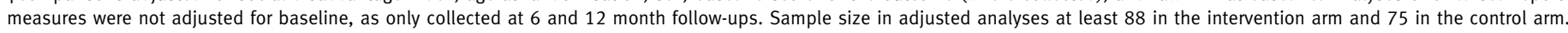
†Values are odds ratios $(95 \% \mathrm{Cl})$. 
Table 4| Outcomes of trial of primary care surveillance and intervention for overweight or obese children, 12 months after randomisation

\begin{tabular}{|c|c|c|c|c|c|c|c|c|}
\hline \multirow[b]{2}{*}{ Outcome } & \multicolumn{2}{|c|}{ Intervention } & \multicolumn{2}{|c|}{ Control } & \multicolumn{2}{|c|}{ Unadjusted difference } & \multicolumn{2}{|c|}{ Adjusted difference $†$} \\
\hline & $\begin{array}{l}\text { No of } \\
\text { participants }\end{array}$ & Measure* & $\begin{array}{c}\text { No of } \\
\text { participants }\end{array}$ & Measure* & Mean $(95 \% \mathrm{Cl})$ & $P$ value & Mean $(95 \% \mathrm{Cl})$ & $P$ value \\
\hline \multicolumn{9}{|l|}{ Anthropometry: } \\
\hline Child BMI & 127 & $20.8(2.8)$ & 115 & $21.0(2.4)$ & $-0.11(-0.77$ to 0.55$)$ & 0.7 & $-0.11(-0.45$ to 0.22$)$ & 0.5 \\
\hline Child waist circumference & 125 & $72.2(9.1)$ & 114 & $72.2(8.4)$ & $-0.02(-2.27$ to 2.22$)$ & 1.0 & $0.12(-1.12$ to 1.37$)$ & 0.8 \\
\hline Maternal BMI & 121 & $28.5(6.0)$ & 110 & $27.2(5.5)$ & $1.29(-0.21$ to 2.79$)$ & 0.09 & $0.41(-0.18$ to 1.00$)$ & 0.2 \\
\hline Paternal BMI & 88 & $27.8(4.0)$ & 78 & $28.2(3.8)$ & $-0.41(-1.62$ to 0.79$)$ & 0.5 & $-0.14(-0.54$ to 0.25$)$ & 0.5 \\
\hline \multicolumn{9}{|l|}{ Accelerometry: } \\
\hline Activity (counts/min) & 110 & $344(136)$ & 91 & $332(131)$ & 12 ( -26 to 49$)$ & 0.5 & 11 ( -26 to 49$)$ & 0.6 \\
\hline$\%$ of time spent in MVPA & 110 & $16.1(5.9)$ & 91 & $15.4(5.5)$ & $0.7(-0.9$ to 2.3$)$ & 0.4 & $0.6(-1.0$ to 2.2$)$ & 0.5 \\
\hline \multicolumn{9}{|l|}{ Parent-proxy report: } \\
\hline "High" v “low" activity & 122 & $21.5 \%$ & 105 & $17.6 \%$ & 1.20 (0.85 to 1.68$) \ddagger$ & 0.3 & 1.23 (0.88 to 1.73$) \ddagger$ & 0.2 \\
\hline Nutrition score & 119 & $3.9(1.0)$ & 104 & $3.7(1.1)$ & $0.2(0.004$ to 0.4$)$ & 0.05 & $0.1(-0.1$ to 0.4$)$ & 0.2 \\
\hline PedsQL total: & 124 & $78.9(12.1)$ & 113 & $75.9(12.8)$ & $3.1(-0.1$ to 6.2$)$ & 0.06 & $3.1(0.2$ to 6.0$)$ & 0.03 \\
\hline Physical summary & 124 & $81.2(17.3)$ & 112 & $79.0(16.0)$ & $2.3(-2.0$ to 6.6$)$ & 0.3 & $2.0(-1.8$ to 5.9$)$ & 0.3 \\
\hline Psychosocial summary & 124 & $77.7(12.0)$ & 113 & $74.4(13.3)$ & $3.3(0.1$ to 6.6$)$ & 0.04 & $3.5(0.6$ to 6.5$)$ & 0.02 \\
\hline \multicolumn{9}{|l|}{ Child self report: } \\
\hline PedsQL total: & 125 & $80.2(12.1)$ & 112 & $79.4(12.7)$ & $0.8(-2.4$ to 4.0$)$ & 0.6 & $1.6(-1.5$ to 4.7$)$ & 0.3 \\
\hline Physical summary & 125 & $83.1(11.1)$ & 112 & $81.2(14.4)$ & $1.9(-1.3$ to 5.2$)$ & 0.2 & $2.4(-0.8$ to 5.7$)$ & 0.1 \\
\hline Psychosocial summary & 125 & $78.6(14.0)$ & 112 & $78.4(13.5)$ & $0.2(-3.3$ to 3.7$)$ & 0.9 & $1.1(-2.3$ to 4.5$)$ & 0.5 \\
\hline Body dissatisfaction & 125 & $0.9(1.1)$ & 112 & $0.9(1.0)$ & $-0.02(-0.29$ to 0.25$)$ & 0.9 & $-0.07(-0.33$ to 0.19$)$ & 0.6 \\
\hline $\begin{array}{l}\text { "Positive" v"negative" appearance/ } \\
\text { self worth }\end{array}$ & 125 & $76.4 \%$ & 112 & $73.8 \%$ & $1.12(0.76$ to 1.67$) \ddagger$ & 0.6 & 1.19 (0.79 to 1.77$) \ddagger$ & 0.4 \\
\hline
\end{tabular}

$\mathrm{BMI}=$ body mass index. MVPA=moderate to vigorous physical activity. PedsQL=paediatric quality of life inventory.

*Values are means (standard deviations) unless stated otherwise.

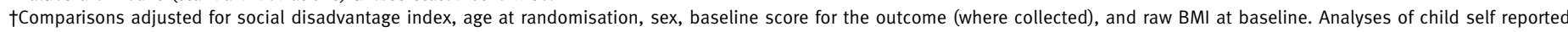

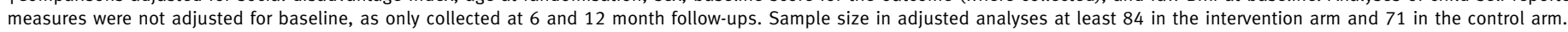

$\ddagger$ Values are odds ratios $(95 \% \mathrm{Cl})$.

children do not meet criteria for the introduction of screening programmes. ${ }^{12}$ Resources may be better divided between primary prevention at the community and population levels, and enhancement of clinical treatment options for children with established obesity.

Contributors: The project was initiated and supervised by MW, JG, LAB, $Z M$, and KG, who also obtained its funding. All authors contributed to developing the protocols and reviewing, editing, and approving the final version of the paper. The trial was implemented by $M W, Z M$, and $B G$, who oversaw all stages. BG and PL carried out recruitment and data collection, with other field workers. LS, Colin Riess, and Helen Cahill contributed

\section{WHAT IS ALREADY KNOWN ON THIS SUBJECT}

With around $25 \%$ of all children worldwide now overweight or obese, hospital services cannot hope to provide adequate weight management services

National policies in many countries (including the US, UK, and Australia) promote primary care surveillance and brief counselling to reduce childhood obesity

Two systematic reviews have highlighted that there is no evidence to support this approach

\section{WHAT THIS STUDY ADDS}

Primary care screening followed by brief counselling did not improve body mass index, physical activity, or nutrition in overweight or mildly obese 5-10 year olds, and the approach would be very costly if universally implemented

These findings are at odds with current national policies

Resources may be better spent on primary prevention strategies at the community and population levels, and on enhancing treatment options medical education planning, implementation, and expertise. Lucy Rogers and Rachel Barratt contributed to recruitment, retention, and data collection from families and general practitioners. OCU conducted the analyses, with the exception of the economic analysis, which was performed by LG. MW and BG wrote the paper, with critical input from the other authors. MW is the guarantor. We thank Colin Riess, Helen Cahill, Lucy Rogers, and Rachel Barratt for their contributions to the project. Funding: This study was funded by the Australian National Health and Medical Research Council (NH\&MRC) Project Grant 334309. MW is supported by NH\&MRC Career Development Award 284556; LG by NH\&MRC Capacity Building Grant 425855; and OCU by NH\&MRC Capacity Building Grant 436914. The researchers were independent of the funders.

Competing interests: None declared.

Ethical approval: The project was approved by the Royal Children's Hospital Ethics in Human Research Committee (EHRC 25006).

1 Wang $\mathrm{Y}$, Lobstein T. Worldwide trends in childhood overweight and obesity. Int J Pediatr Obes 2006;1:11-25.

2 Lobstein T, Baur L, Uauy R, for IASO International Obesity Taskforce. Obesity in children and young people: a crisis in public health. Obes Rev 2004;5:4-85.

3 Gortmaker SL, Must A, Perrin MJ, Sobol AM, Dietz WH. Social and economic consequences of overweight in adolescence and young adulthood. N Engl J Med 1993;329:1008-12.

4 Ebbeling CB, Pawlak DB, Ludwig DS. Childhood obesity: publichealth crisis, common sense cure. Lancet 2002;360:473-82.

5 Gerner B, McCallum Z, Sheehan J, Harris C, Wake M. Are general practitioners equipped to detect child overweight/obesity? Survey and audit. J Paediatr Child Health 2006;42:206-11.

6 Waters E, Haby H, Wake M, Salmon L. Public health and preventive healthcare in children: current practices of Victorian GPs and barriers to participation. Med J Aust 2000;173:98-71.

7 UK Department of Health. Obesity care pathway and your weight, your health. www.dh.gov.uk/PublicationsAndStatistics/

Publications/PublicationsPolicyAndGuidance/ PublicationsPolicyAndGuidanceArticle/fs/en? CONTENT_ID=4134408\&chk=Sq/wNd (accessed 28 Apr 2008). 
8 American Academy of Pediatrics: Committee on Nutrition. Prevention of pediatric overweight and obesity. Pediatrics 2003;112:424-30.

9 National Health and Medical Research Council. Clinical practice guidelines for the management of overweight and obesity in children and adolescents. Canberra: Commonwealth of Australia, 2003.

10 Moyer VA, Butler M. Gaps in the evidence for well-child care: a challenge to our profession. Pediatrics 2004;114:1511-21.

11 Whitlock EP, Williams SB, Gold R, Smith PR, Shipman SA. Screening and interventions for childhood overweight: a summary of evidence for the US Preventive Services Task Force. Pediatrics 2005;116:e125-44.

12 Westwood M, Fayter D, Hartley S, Rithalia A, Butler G, Glasziou P, et al. Childhood obesity: should primary school children be routinely screened? A systematic review and discussion of the evidence. Arch Dis Child 2007;92:416-22.

13 McCallum Z, Wake M, Gerner B, Baur L, Gibbons K, Gold L, et al. Outcome data from the LEAP (Live, Eat and Play) trial: a randomized controlled trial of a primary care intervention for childhood overweight/mild obesity. Int J Obes 2007;31:630-6.

14 Schwartz RP, Hamre R, Dietz WH, Wasserman R, Slora E, Myers E, et al. Office-based motivational interviewing to prevent childhood obesity: a feasibility study. Arch Pediatr Adolesc Med 2007;161:495-501.

15 Prochaska JO, DiClemente CC. Stages of change in the modification of problem behaviors. Prog Behav Modif 1992;28:183-218.

16 Turnell A, Hopwood L. Solution-focused brief therapy. Case Stud Brief Fam Ther 1994;8:39-51.

17 Cole TJ, Bellizzi MC, Flegal KM, Dietz WH. Establishing a standard definition for child overweight and obesity worldwide: international survey. BM/ 2000;320:1240-3.

18 Cole TJ, Green PJ. Smoothing reference centile curves: the LMS method and penalized likelihood. Stat Med 1992;11:1305-19.

19 Cole TJ. Growth monitoring with the British 1990 growth reference. Arch Dis Child 1997;76:47-9.

20 McCallum Z, Wake M, Gerner B, Harris C, Gibbons K, Gunn J, et al. Can Australian general practitioners tackle childhood overweight/ obesity? Methods and processes from the LEAP (Live, Eat and Play) randomized controlled trial. J Paediatr Child Health 2005;41:488-94.

21 Greenberg G, Ganshorn K, Danilkewich A. Solution-focused therapy. Counselling model for busy family physicians. Can Fam Physician 2001;47:2289-95.

22 Ogden CL, Kuczmarski RJ, Flegal KM, Mei Z, Guo S, Wei R, et al. Centers for Disease Control and Prevention 2000 growth charts for the United States: improvements to the 1977 National Center for Health Statistics version. Pediatrics 2002;109:45-60.

23 Australian Bureau of Statistics. 2001 Census of population and housing: Socio-economic indexes for areas. ABS catalogue 2039.0. Canberra: Commonwealth of Australia, 2003.

24 Australian Government Department of Health and Ageing. Medicare benefits schedule book 2006 (valid 1/11/06-30/10/07). Canberra: Australian Government, 2006.

25 Stata Corporation. Stata Statistical Software: Release 9.2. College Station, TX: Stata, 2005.

26 Goldstein H. Multilevel Statistical Models. 2nd ed. London: Arnold, 1995.

27 Hanley JA, Negassa A, Edwardes MD, Forrester JE. Statistical analysis of correlated data using generalized estimating equations: an orientation. Am J Epidemiol 2003;157:364-75.

28 Davidson AC, Hinkley DV. Bootstrap methods and their application. Cambridge: Cambridge University Press, 1997.

29 Wilfley DE, Stein RI, Saelens BE, Mockus DS, Matt GE, Hayden-Wade HA, et al. Efficacy of maintenance treatment approaches for childhood overweight: a randomized controlled trial. AMA 2007;298:1661-73.

30 Savoye M, Shaw M, Dziura J, Tamborlane W, Rose P, Guandalini C, et al. Effects of a weight management program on body composition and metabolic parameters in overweight children: a randomized controlled trial. JAMA 2007;297:2697-704.

31 Golley RK, Magarey AM, Baur LA, Steinbeck KS, Daniels LA. Twelvemonth effectiveness of a parent-led, family-focused weightmanagement program for prepubertal children: a randomized, controlled trial. Pediatrics 2007;119:517-25.

32 Kalavainen MP, Korppi MO, Nuutinen OM. Clinical efficacy of groupbased treatment for childhood obesity compared with routinely given individual counseling. Int J Obes 2007;31:1500-8.

33 Hughes AR, Stewart L, Chapple J, McColl JH, Donaldson MD, Kelnar CJ, et al. Randomized, controlled trial of a best-practice individualized behavioral program for treatment of childhood overweight: Scottish Childhood Overweight Treatment Trial. Pediatrics 2008;121:e539-46.

34 Varni JW, Burwinkle TM, Seid M, Skarr D. The PedsQL 4.0 as a pediatric population health measure: feasibility, reliability, and validity. Ambul Pediatr 2003;3:329-41.

35 Collins ME. Body figure perceptions among preadolescent children. Int J Eat Dis 1991;10:199-208.

Accepted: 14 April 2009 